NEWS

\title{
Weighing up the evidence
}

\section{A meta-analysis of clinical trials for the diabetes drug Avandia has hinted at possible cardiovascular risks; but how clear is the study, and how should meta-analyses be viewed against clinical trials?}

The day after concerns about Avandia hit the news, the emergency room at New York City's Bellevue Hospital was even more hectic than usual. Patients with diabetes filed in and asked to discontinue their medication while the phone rang with calls from other Avandia users. Harried doctors rushed to handle the extra flow.

Cardiologist James Underberg found the scene disturbing. Although he insists that he is a clinician, not a statistician, Underberg could see that the analysis that suggested Avandia might be causing heart attacks was plagued by limitations - the authors

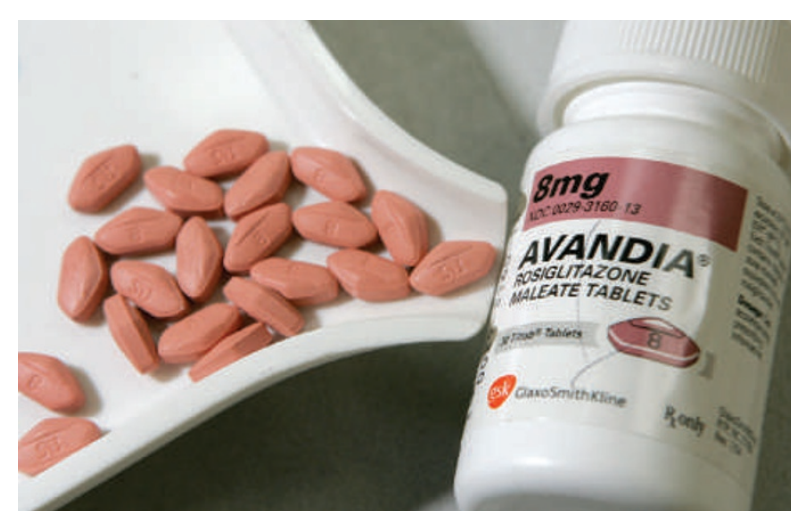

An analysis of Avandia trials has highlighted potential side effects.

tistical tools to uncover the side effects of drugs. They were key in bringing to light the increased chance of heart attack associated with the painkiller Vioxx (also highlighted by Nissen, see 'Man on a mission'), and the added risk of suicidal thinking and behaviour in children taking some antidepressants. Few doubt that meta-analyses have their uses, but researchers caution that they should be read in the right light and, if possible, made more robust.

The studies crunched together in this case were not designed to look for cardiovascular side effects, but rather to assess the drug's main activity. Reports of heart of the paper said so themselves. But he could now be sued the next time he writes a prescription for Avandia, he says, "all on the basis of one article that may or may not have significant flaws in the analysis".

The article, published last week (S. E. Nissen and K. Wolski N. Engl. J. Med. doi:10.1056/ NEJMoa072761; 2007), is a meta-analysis of 42 clinical trials of rosiglitazone, a drug used to lower blood sugar in patients with diabetes and marketed under the name Avandia by London-based pharmaceutical giant GlaxoSmithKline (GSK). The authors, Steven Nissen and Kathy Wolski of the Cleveland Clinic in Ohio, found that the chance of having a heart attack was $43 \%$ higher in patients who were taking the drug than in those who weren't, although precisely why is unclear (see 'How Avandia works').

These data do not differ strikingly from oth-

ers that have come before; in Europe, Avandia comes with a warning label that the drug increases the risk of heart attack by $31 \%$, on the basis of a previous meta-analysis, by GSK. But the new paper has caught a lot of attention. The Lancet, which had earlier published the promising results of one of GSK's clinical trials of Avandia, responded with an editorial warning against alarmist responses to Nissen and Wolski's paper and its tone of "urgency" (Lancet

"If I saw a metaanalysis done by GSK on Avandia, I don't think I would believe it." incidents may not have followed the same rigorous criteria in all studies, nor were they reviewed by an outside panel. And Nissen and Wolski had access only to the trials' summaries, and not to patient-specific data (GSK has posted such summaries online since an unrelated court case in 2004 prompted it to do so), so any confounding effects could not be taken into account. If the cardiovascular risks are only for a specific subset of patients, this meta-analysis won't be able to tell. doi:10.1016/S0140-6736(07)60787-9; 2007). But by then, GSK's stock price had plummeted and congressional hearings had been scheduled to review the handling of the drug by the US Food and Drug Administration (FDA).

Meta-analyses, which crunch together the results of many clinical trials, are powerful sta-

\section{How Avandia works}

How does a drug that lowers blood sugar levels cause heart attacks? Avandia (rosiglitazone) is a member of a troubled class of drugs called thiazolidinediones that activate a set of receptors in cell nuclei. These receptors the peroxisome proliferatoractivated receptors - then modulate the expression of multiple genes. The full physiological consequences of tweaking this expression are not known, and it comes as little surprise that the drugs have multiple effects. Another drug in this class was taken off the market because it caused liver damage, and attempts to develop other thiazolidinediones have encountered problems with other harmful side effects.

Rosiglitazone raises levels of low-density lipoprotein cholesterol - the "bad cholesterol' that is associated with cardiovascular problems The drug also slightly lowers haemoglobin concentrations, which can increase stress on the heart. Most doctors agree that the magnitude of these changes wouldn't be sufficient to boost the risk of heart attack by $43 \%$, but as the absolute value of heart-attack risk calculated by Nissen's meta-analysis is in question, both of these mechanisms remain possible culprits. H.L.
To make such studies more robust, more data are needed. John Ioannidis, an epidemiologist at the University of Ioannina School of Medicine in Greece who has examined numerous meta-analyses notes that journal articles reporting clinical trials tend to dedicate more space to listing the authors' names than to listing possible side effects associated with the drug. And studies that produce negative results are often not published at all, giving researchers an incomplete picture of how often trials fail. Ioannidis argues that use of complete data sets would strengthen the analysis and could weed out potential false alarms. "I think that companies would actually gain from such transparencies," he says.

He adds that meta-analyses should be done by independent groups. At the moment, they are frequently conducted as part of the drug approval process. But in many such cases, the analysis is being done by the pharmaceutical companies that manufacture the drug in question - something that most agree is not a good idea. "If I saw a meta-analysis done by GSK on Avandia, I don't think I would believe it," 
says Ioannidis. "Someone who is independent should do this."

But GSK doesn't think that crunching studies together is in itself the best way to find side-effects. "We don't think meta-analysis is the best way to address this," says GSK spokeswoman Alice Hunt. Clinical trials, she argues, are the only way to achieve a definitive answer. GSK is in the middle of a clinical trial of more than 4,000 patients that is aimed specifically at assessing the cardiovascular effects of Avandia (compared with more than 10,000 patients in Nissen's number crunch). The Lancet editorial also recommends waiting for these results - although the news of the new findings has reportedly led to volunteers dropping out of the trial.

Preliminary results of the trial, scheduled to finish in 2008, have been shared with the FDA, says Hunt. "They could potentially be released, but that's not being looked at, at the moment," she adds.

The FDA will not as yet comment on the ongoing trial, to "preserve the study integrity", but it does have additional data on the drug. Without seeing the results for themselves, some doctors find it hard to know how to judge FDA assurances that the additional data it has do not point to a significant risk of heart attack. "They are unpublished, uncited data that are not available to the public. I've heard the same story before: 'We know there are weapons of mass destruction in Iraq. We can't tell you how we know, but we know," says Nissen.

For some, even a preliminary analysis is reason enough to avoid the drug, if only because there is an alternative medication - pioglitazone, marketed under the name Actos in the United States - that has not yet been associated with cardiovascular risks. Nissen's analysis was enough to convince Harlan Krumholz, a cardiologist at Yale University: "When you're talking about safety and you're talking about a drug for which there are alternatives, you have to ask yourself, who has the burden of proof here?"

Although Avandia's fate remains unclear, Nissen's study has served to raise the profile of meta-analyses. Roger Chou, a clinician at the Oregon Evidence-based Practice Center in Portland notes that at the moment, independent analyses such as this are done on an ad-hoc basis. "Right now, it's really just when somebody's interested in it, or when there's something that's making people concerned," he says. But there is a growing interest in independent groups monitoring drug safety in this way and, importantly, signs of increased funding from organizations such as the US Agency for Healthcare Research and Quality to support meta-analyses.

Heidi Ledford

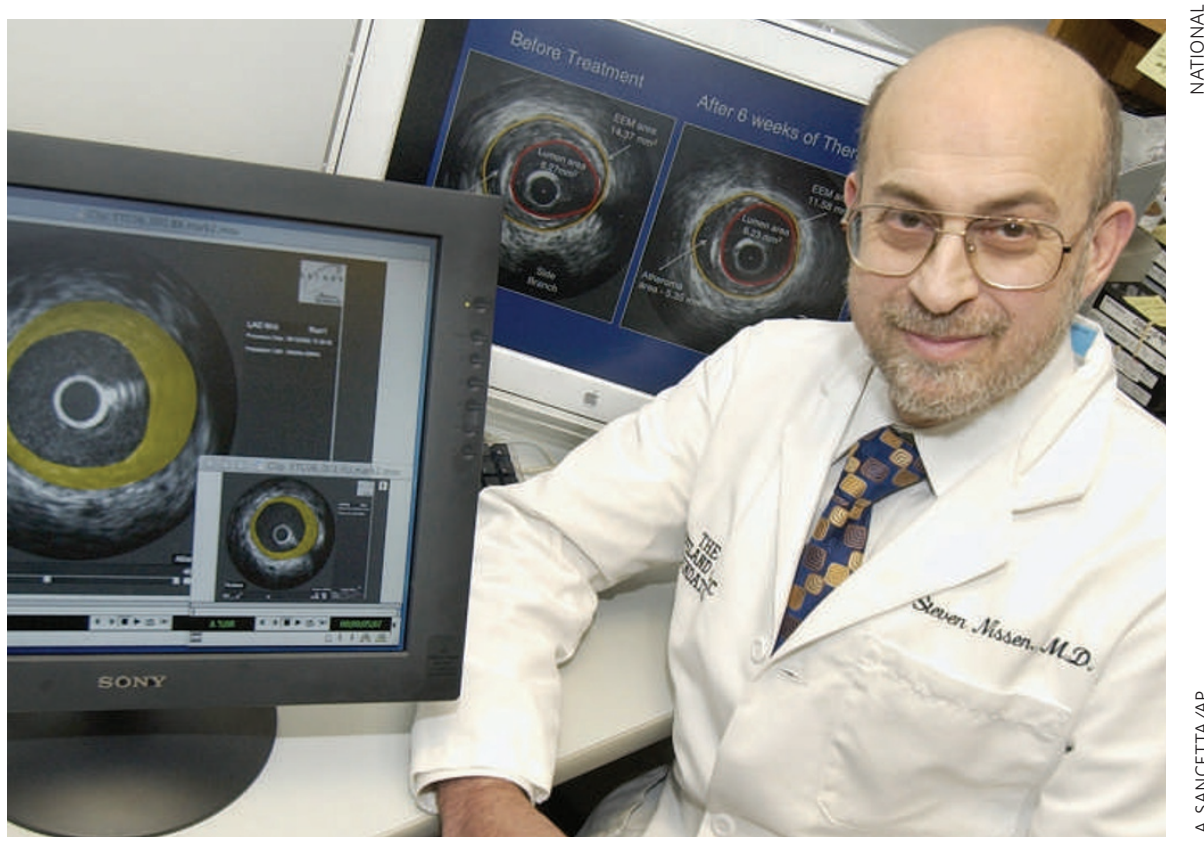

\section{Man on a mission}

It isn't every clinical scientist who in the space of a month sends a major drug company's stock plummeting, is invited to testify at Congress and is crowned one of the world's 100 most influential people by Time magazine. But then, they aren't Steven Nissen, the cardiologist who last week fingered the diabetes drug Avandia as carrying a possible risk of heart attacks (see is right." opposite).

This is not the first or most famous case for Nissen, 58 , who is based at the Cleveland Clinic in Ohio. In 2001, while serving on a committee of external advisers to the US Food and Drug Administration (FDA), he raised concerns about the safety of a painkiller called Vioxx. Before then, he had made his name pioneering an ultrasound technique that allowed doctors to see fatty plaques of atherosclerosis (see Nature Med. 11, 700; 2005).

Since Vioxx, Nissen says that he has become more concerned about the scientific rigour of drug regulation, prompting him to dig into clinical-trial data that suggest hidden drug risks. "I don't go looking for these things, but they sure seem to find me," he says. Between running trials for several drug companies, he has flagged cardiovascular risks in drugs for everything

from attention deficit hyperactivity disorder to heart failure itself, often costing companies

millions in the process.

His fans praise him for refusing to pull his punches. "He will persevere for what he believes is right, regardless of the toes on which he may tread," says Peter Libby, chief of cardiology at Brigham and Women's Hospital in Boston, Massachusetts, who has worked with Nissen for twelve years.

But his methods have earned him enemies, too, many of whom contend that he is more interested in felling the next Goliath than in seeking scientific truth. "The caped crusader Nissen is at it again," groused a critic on the Wall Street Journal's health blog on 21 May. Bob Temple, director of medical policy at the FDA's drug review centre, has also taken a shot at Nissen. Temple told RPM Report that he was "sort of stunned" by Nissen's suggestions to Congress that senior FDA officials had overruled their underlings' safety concerns. "I can tell you, he didn't see that," Temple said.

Nissen certainly isn't always right. Speaking to journalists last October, he put Pfizer's cholesterol drug torcetrapib, for which he was overseeing a clinical trial, at the top of a list of hot stories that reporters should watch in 2007. Weeks later, Pfizer pulled the plug on the drug when it was found to raise death rates in latestage trials (see Nature 444, 794-795; 2006).

"After the torcetrapib business, I thought I would lay low for a while," Nissen said last week. "Then I stumble across this [Avandia] problem and here we are again." Meredith Wadman 